\title{
Impact of agronomic and climatic factors on the mycotoxin content of harvested oats in the UK
}

\author{
by Edwards, S.G.
}

Copyright, Publisher and Additional Information: This is the author accepted manuscript. The final published version (version of record) is available online via Taylor \& Francis.

Please refer to any applicable terms of use of the publisher.

DOI: http://dx.doi.org/10.1080/19440049.2017.1372639 


\section{Impact of agronomic and climatic factors on the mycotoxin content of harvested oats in the UK \\ Simon G. Edwards \\ Accepted manuscript \\ Food Additives and Contaminants \\ $7^{\text {th }}$ August 2017}

Harper Adams University, Newport, Shropshire TF10 8NB, UK

E-mail: sedwards@harper-adams.ac.uk

A survey was conducted to determine the concentration of fusarium mycotoxins in UK oats over three seasons (2006-2008). One hundred oat samples were collected each year at harvest, together with agronomic details, and analysed for ten fusarium mycotoxins. The incidence and concentration of most fusarium mycotoxins, including deoxynivalenol and zearalenone, were relatively low in oats compared to values previously reported for wheat. HT-2 toxin (HT2) and T-2 toxin (T2) levels were relatively high with an overall combined (HT2+T2) mean of $450 \mu \mathrm{g} \mathrm{kg}^{-1}$ for 2006-2008. Data was combined with a previous dataset collected from 2002-2005 to determine the effects of agronomic practices and climate. There was a negative relationship with late summer rainfall, indicating that drier conditions in July and August resulted in increased HT2 and T2 in UK oats. Agronomic factors that impacted upon HT2 and T2 in harvested oats were previous crop, cultivation and variety. Analysis of the previous cropping history showed there was a stepwise increase in HT2+T2 as the cereal intensity of the rotation increased. Variety was an important factor with higher levels and a wider range detected on winter compared to spring varieties. Indicative levels for HT2 and T2 in cereals and cereal products were introduced by the European Commission in 2013. The indicative level for unprocessed oats for human consumption is a combined concentration (HT2+T2) of $1000 \mu \mathrm{g} \mathrm{kg}^{-1}$. From 2002-2008, between 1 and 30\% of samples exceeded $1000 \mu \mathrm{g} \mathrm{kg}^{-1} \mathrm{HT} 2+\mathrm{T} 2$ each year (overall mean 16\%). The introduction of European legislation on HT2 and T2 mycotoxins could have serious implications for UK oat production and oat processing industries based on the levels detected within these studies.

Keywords: trichothecene; deoxynivalenol; HT-2 toxin; T-2 toxin; zearalenone; variety; rotation; cultivation 


\section{Introduction}

Fusarium head blight (FHB) of cereals may be caused by several fungal pathogens. The disease is also referred to as fusarium ear blight or scab, or fusarium panicle blight for oats. The vast majority of research conducted on FHB is concerned with wheat as this is the most economically important small grain cereal world-wide and is the most susceptible to FHB and mycotoxin contamination in many countries (Osborne and Stein 2007, Parry et al. 1995). The trichothecene mycotoxins are produced by some of the fusarium head blight pathogens and their level within grain depends on weather conditions. High humidity around flowering is conducive to head blight epidemics and mycotoxin production (Osborne and Stein 2007). Deoxynivalenol (DON) is the most commonly detected trichothecene in cereals and is produced predominantly by F. graminearum (Fredlund et al. 2013, Hofgaard et al. 2016, Schöneberg et al. 2016). Nivalenol (NIV) can be produced by some strains of $F$. graminearum and F. culmorum, however studies show that $F$. poae is commonly linked to high levels of NIV (Hofgaard, et al. 2016, Schöneberg, et al. 2016). HT2 and T2 are Type A trichothecenes, which are thought to be produced predominantly by F. langsethiae (Edwards et al. 2012, Fredlund, et al. 2013, Hofgaard, et al. 2016)

Surveys of cereal products have indicated that fusarium mycotoxins are a common contaminant of human and animal diets with highly skewed distribution with most samples containing low concentrations (JECFA 2011). At high concentrations DON causes reduced feed intake, reduced weight gain and vomiting in farm animals (Anon 2004). Nausea, vomiting, diarrhoea, abdominal pain, headache, dizziness and fever have been reported when high concentrations of DON were consumed by humans (Anon 1999). Other trichothecenes have the same cellular activity which is disruption of protein synthesis, and have a higher cellular toxicity than DON. Nivalenol and T2 are ca. 20 times more toxic than DON, although the relative differences are dependent on the target cell or animal studied (Desjardins 2006). HT2 and T2 are believed to be associated with Alimentary Toxic Aluekia caused by the consumption of cereals which had overwintered in fields in Russia in the 1940s (Desjardins 2006). Tolerable Daily Intakes (TDI) have been set for several Fusarium mycotoxins. The TDI is deemed to be the maximum amount that is safe to consume every day for a lifetime. It may therefore be safe to exceed this limit occasionally with no impact on health. A provisional maximum TDI for DON and its acetylated forms is $1 \mu \mathrm{g} \mathrm{kg}^{-1}$ body weight/day was set by the Joint WHO/FAO Expert Committee on food Additives (JECFA 2011). In 2011, the European Food Safety Authority set a combined (HT2+T2) TDI of $0.1 \mu \mathrm{g} \mathrm{kg}^{-1}$ body weight/day (EFSA Panel on Contaminants in the Food Chain 2011). An even lower group TDI for HT2, T2 and their modified forms was set by EFSA at $0.02 \mu \mathrm{g} \mathrm{kg}^{-1}$ body weight/day (EFSA Panel on Contaminants in the Food Chain 2017). The European Commission (EC) has set legislative limits for the fusarium mycotoxins including DON and ZON in cereal 
grains and cereal-based products intended for human consumption (Anon. 2006). Of the other trichothecenes, the only ones currently being considered for legislation are HT2 and T2 toxins. Indicative levels for these mycotoxins were introduced in 2013 (Anon 2013) based on the combined concentration of the two toxins (HT2+T2). The indicative level for unprocessed oat grains for human consumption is $1000 \mu \mathrm{g} \mathrm{kg}^{-1} \mathrm{HT} 2+\mathrm{T} 2$. The EC Recommendation requests Member States in collaboration with industry to monitor HT2 and T2 concentrations in cereals and cereal products. Where indicative levels are exceeded, factors resulting in the occurrence of the high concentrations and measures to avoid or reduce such high levels occurring should be determined.

Few studies have compared the FHB severity or mycotoxin contamination of wheat, barley and oats either from replicated field experiments or observational studies. In western Canada, observational data showed highest deoxynivalenol (DON) content was found on wheat, then barley, and lowest amounts on oats from 1991 to 1998 (Campbell et al. 2002). The percentage of samples exceeding $1000 \mu \mathrm{g} \mathrm{kg}^{-1}$ DON was 31, 22 and 1.4\% for wheat, barley and oats, respectively. This data was matched in a study of head blight susceptibility of cereal species in inoculated glasshouse experiments (Langevin et al. 2004). In the epidemic years of 1993 and 1994 in Minnesota commercial cereal samples were analysed for DON. Average DON concentrations in wheat, barley and oat samples were 8.3, 10.4, and 1.4 ppm, respectively (Jones and Mirocha 1999). There is less data on the relative concentration of other fusarium mycotoxins in wheat, barley and oats. For HT2 and T2, highest levels were detected on oats, then barley and lowest in wheat samples in Norway (Bernhoft et al. 2010, Hofgaard, et al. 2016).

There is limited data on occurrence of fusarium mycotoxins in UK cereals prior to 2001. A previous survey conducted in 1999 found highest amounts of DON on wheat, with lower levels on barley and oats. From 2002-2005, fusarium mycotoxins were quantified in wheat, barley and oats (Edwards 2009a, Edwards 2009b, Edwards 2009c). For DON and ZON, highest levels were detected in wheat, with much lower levels in barley and oats. In contrast to this, HT2 and T2 were high in oats with much lower levels in barley and wheat. A more recent survey of wheat, barley and oats in the UK also indicated that oats had a significantly higher HT2+T2 content compared to wheat and barley (Opoku et al. 2013). Subsequent field experiments, where wheat, barley and oats were grown together under identical agronomy, identified that the higher concentration was primarily due to genetic differences between the cereal species rather than agronomic ones (Opoku et al. In press).

In Norway, a large scale survey over 6 years identified that highest DON concentrations occurred in oat samples, then wheat, and barley had the lowest DON average concentrations (Langseth and Elen 1996). The same degree of variation in contamination levels between cereals 
was not observed in field experiments indicating that the observed differences were not solely due to genetic differences between the cereal species but also due to differences in agronomy.

The relative degree of mycotoxin contamination between cereals will vary between years and between regions depending on climatic conditions when each host species is a susceptible growth stage. This variation will also exist between winter and spring sown varieties of the same host species. It should also be noted that the relationship between cereals and head blight is not a static one and changes have been observed over recent years. For example, in Nordic countries there has been a recent increase in F. graminearum infection and corresponding DON concentrations in cereals (Fredlund, et al. 2013, Hietaniemi et al. 2016, Hofgaard, et al. 2016). This may have been due to a fundamental shift in the pathogen population, or changes in agronomy and/or climate.

The majority of research on the impact of agronomic factors on the mycotoxin content of cereals has been conducted on DON in wheat. These studies identified previous crop, cultivation, variety and fungicides can all have a significant impact (e.g. Edwards 2004, Gourdain et al. 2011, Lori et al. 2009, Wegulo 2012). Orlando et al. (2009) identified significantly lower HT2+T2 in French barley crops after a non-cereal crop in the rotation and in winter compared to spring sown crops. An analysis of organic and conventional oat samples in Norway identified significantly lower HT2 in oat crops that followed a non-cereal in the crop rotation (Bernhoft et al. 2012). Other agronomic factors analysed (fertilisers, fungicide, herbicide, insecticide, plant growth regulator and catch crop) had no significant effect on HT2 concentrations. Edwards and Anderson (2011) analysed HT2+T2 content of oat samples from eight field experiments and found no significant effect of nitrogen fertiliser, plant growth regulators or fungicides.

There is limited data on the impact of weather on HT2+T2 levels in cereals. Xu et al. (2014) used window pane analysis to identify that rain in May (oats at booting stage) increased HT2+T2 whereas dry weather after May (oats from flowering onwards) reduced HT2+T2 in UK harvested oats. In a Norwegian study (Bernhoft, et al. 2012), only high humidity before harvest significantly increased HT2 concentrations. A more recent Norwegian study (Hjelkrem et al. In press) appears to confirm both previous studies with high moisture at booting and pre-harvest and dry conditions between these growth stages increasing HT2+T2 risk.

A recent review of mycotoxins in organic and conventional cereals identified that the majority of studies did not find a significant difference between DON levels in organic and conventional wheat but did find significantly lower HT2+T2 in organic compared to conventional oat samples (Brodal et al. 2016). In the previous UK oat study (Edwards 2009b), there were large differences between organic and conventional oats with organic oats having ca. five times lower HT2+T2 compared to conventional samples. Less extreme differences, but still significantly lower 
HT2+T2 in organic oats have also been reported in Norway (Bernhoft, et al. 2010) and Germany (Gottschalk et al. 2007). Results from north-west Poland were reported to be significantly lower for organic samples from 2009-2011 (Twaruzek et al. 2013) but not significantly different for samples from south-east Poland from 2006-2008 (Kuzdralinski et al. 2013).

The aims of this study were to determine the range of fusarium mycotoxin concentrations within harvested UK oat grain over a three year period (2006-2008) and to determine how agronomic factors and climate affect the concentration of fusarium mycotoxins in harvested oat grain in the UK.

\section{Material and Methods}

\section{Grain sample collection}

Each year 100 grain samples of conventional oats (2006-2008) and related agronomic data were collected by crop consultants. Samples were collected at harvest from specific fields either from the combine or from trailers leaving the field. Approximately $300 \mathrm{~g}$ sub-samples were taken from ten arbitrary points around the field and combined to provide a $3 \mathrm{~kg}$ sample. Consultants sent these samples in cotton bags by overnight courier along with agronomic data pertaining to that field sample. The survey was stratified to receive an equivalent number of samples from four regions of England (South, East, Midlands, North), Scotland and Northern Ireland. Agronomy details requested included location, variety, intended end use, previous crops for last 4 years, crop debris management, cultivation technique and fungicide applied at flowering.

On receipt of samples their moisture content was determined, if above $18 \%$ moisture content the samples were dried overnight on a hot air drier before further processing. A $500 \mathrm{~g}$ sub-sample of grain was removed using a ripple divider, dried to $12 \%$ moisture content and stored at room temperature as an archive grain sample. The remaining sample was milled (ZM100 centrifugal mill, Retsch UK) with a $1 \mathrm{~mm}$ screen, mixed in a tumbler mixer before two $200 \mathrm{~g}$ sub-samples were collected. One sample was sent to Campden BRI for mycotoxin analysis, the remaining sample was held as an archive flour sample at $-20^{\circ} \mathrm{C}$.

\section{Mycotoxin analysis}

All samples were analysed by a commercial service provided by Campden BRI (Chipping Campden, UK) using UKAS accredited procedures. The trichothecenes deoxynivalenol (DON), nivalenol (NIV), 3-acetylDON, 15-acetylDON, fusarenone X, T2 toxin, HT2 toxin, diacetoxyscirpenol (DAS) and neosolaniol (NEO) and the non-trichothecene, ZON were analysed 
by LC/MS/MS. Samples were extracted by acetonitrile/water (80:20) and cleaned using a solid phase extraction. Spiked samples were included in each batch to determine extraction recovery and stable isotope labelled internal standards were used for DON and ZON. The limit of quantification (LoQ) for the trichothecenes was $10 \mu \mathrm{g} \mathrm{kg}^{-1}$ and for ZON was $2 \mu \mathrm{g} \mathrm{kg}^{-1}$.

\section{2-2005 dataset}

A survey using similar methodology was conducted during the harvest years of 2002-2005 (Edwards 2009b). A total of 458 samples (115 organic and 343 conventional samples) were collected and analysed for fusarium mycotoxins. Agronomy data available for these samples included location, variety, intended end use, previous crop, cultivation technique and fungicides applied at flowering.

\section{Statistical analysis}

For statistical purposes, samples with a mycotoxin content below the LoQ were assigned a value of (LoQ)/2. Summary statistics (percentage greater than $10 \mu \mathrm{g} \mathrm{kg}^{-1}$, mean, median, $90^{\text {th }}$ percentile, $95^{\text {th }}$ percentile and maximum) were calculated using Excel (Microsoft v.2010). All other statistical analysis was completed using Genstat (Lawes Agricultural Trust, v14). Relationships between mycotoxin concentrations were determined using regression analysis. For modelling the mycotoxin concentration of samples, data from a previous study (2002-2005; (Edwards 2009b)) was also included. Mycotoxin concentrations were $\log _{10}$ transformed and analysed using a normal distribution. Significant agronomic factors were selected for the model using a stepwise selection ANOVA. After selection of factors to be used in the model the data file was filtered of all samples containing blanks within these factors and the data was re-analysed. Temporal (year) and spatial (region) factors were forced into the model. Other agronomic factors were ordered based on the order in which they occur within a growing season. Interactions between factors were entered into the model where there was a biological reason to expect one to occur. As weather is an important parameter of fusarium head blight epidemiology, one could expect a temporal (year) and spatial (region) interaction. As crop debris is an important parameter of fusarium head blight epidemiology, as in the type and amount of crop debris, then one could expect an interaction between previous crop, crop debris management and the method of cultivation. For cultivation, min-till and direct drilled were combined as min-till as only five samples were supplied after direct drilling. All varieties and previous crops with less than 10 samples were entered as "Other".

Four datasets were analysed:

1. 2002-2005 agronomic factors including practice (organic or conventional) 
2. 2002-2005 (conventional only) and 2006-2008 combined where agronomic factors were present for both datasets.

3. 2006-2008 for new agronomic factors

4. 2006-2008 restricted to samples with full cropping history for previous four years analysed for cereal intensity.

Monthly rainfall data for England and Wales was obtained from the UK Met Office HADUKP data (Alexander and Jones 2000). Annual average HT2+T2 concentrations were correlated to UK total monthly rainfall for June, July and August as single months, two months and all three months. Various weightings for harvest rainfall were attempted based on the rationale that with greater rainfall in July then the UK oat harvest will extend longer into August. The final weighting based on the highest variance accounted for within regression models of mycotoxin concentrations was calculated as rainfall for July plus a contribution from August rainfall weighted by July rainfall divided by one hundred (July $+[\mathrm{July} / 100]^{*}$ August).

\section{Results}

\section{Summary statistics}

In total 303 samples of oats were collected and analysed for mycotoxins. Of the ten fusarium mycotoxins analysed, eight were detected, of these DON, NIV, HT2, T2, T2 triol and NEO were detected above $100 \mu \mathrm{g} \mathrm{kg}^{-1}$. Average recoveries for detected mycotoxins ranged from $70 \%$ (NIV) to $93 \%$ (ZON). The expanded measurement of uncertainty ranged from $23 \%$ (DON) to $37 \%$ (15Acetyl DON). Average recoveries and expanded measurements of uncertainty for all mycotoxins analysed are presented in Supplementary Table 1. Table 1 shows the percentage above $10 \mu \mathrm{g} \mathrm{kg}^{-1}$ (the limit of quantification for trichothecenes), the mean, median, the 90th percentile, the 95th percentile and the maximum concentration for each mycotoxin detected. Combined values are provided for HT2 and T2. All individual mycotoxin results are available as Supplementary Data.

\section{[Insert Table 1]}

The distribution of all mycotoxins detected was skewed as can be seen by the large difference between the mean and median values. HT2 was the most frequently detected fusarium mycotoxin and was usually present at the highest concentration (Table 1). Nivalenol was detected in a high percentage of samples ( $73 \%$ above $\left.10 \mu \mathrm{g} \mathrm{kg}^{-1}\right)$ but was never present at a high concentration $(>1000$ 
$\mu \mathrm{g} \mathrm{kg}^{-1}$ ). DON was only an occasional contaminant of oats (32\% above $10 \mu \mathrm{g} \mathrm{kg}^{-1}$ ). The acetyl derivative of NIV, fusarenone X (FX), was detected at low concentrations in three samples in 2007. Acetyl derivatives of DON were not detected in any sample $\left(\mathrm{LoQ}=10 \mu \mathrm{g} \mathrm{kg}^{-1}\right)$. ZON was rarely detected, $14 \%$ of samples above the LOQ of $2 \mu \mathrm{g} \mathrm{kg}$-1 and $6 \%$ of samples exceeded $10 \mu \mathrm{g} \mathrm{kg}^{-1}$. The relationships within and between the type $\mathrm{A}$ and type $\mathrm{B}$ trichothecenes were similar to those reported previously (Edwards, 2009) with positive correlations between HT2, T2 and NEO and no relationship between DON and NIV or between these and the type A trichothecenes (results not shown).

For the combined dataset of 2002-2008, the EU legal limits for DON (1750 $\left.\mathrm{g} \mathrm{kg}^{-1}\right)$ and ZON (100 $\mu \mathrm{g} \mathrm{kg}^{-1}$ ) were only exceeded in 2008 ( 1 and 6\%, respectively, Table 2 ) which is thought to be a result of the delayed, wet harvest that year. The number of samples exceeding the EU indicative level for HT2+T2 (1000 $\left.\mathrm{g} \mathrm{kg} \mathrm{k}^{-1}\right)$ ranged from 1-30\% with an overall mean of $16 \%$ (Table 2). It should be noted that these were not stratified surveys based on oat production within each area and as such the results may not be an accurate representation of UK oat production.

[Insert Table 2]

\section{Statistical modelling for HT2+T2 in oats}

The aim of the statistical modelling was to determine the effect of agronomic factors on the fusarium mycotoxin contamination of oats.

\section{Dataset 1 2002-2005 (n=407)}

The agronomic factors entered for selection were:

- Year*region

- Practice (organic or conventional)

- Previous crop*cultivation

- Variety

(* indicates an interaction)

All factors were significant $(\mathrm{p}<0.05)$ but there was multicollinearity within the dataset so that the variance allocated to each factor was strongly influenced by their position within the model. If practice was placed at the front of the model (after year and region) it accounted for $15 \%$ of the total variance $(\mathrm{p}<0.001)$ whereas if it was placed at the end it accounted for $3.5 \%$ of the total variance $(\mathrm{p}<0.001)$. The concentration of HT2+T2 in organic samples was ca. five times lower in organic as compared to conventional samples as reported previously (Edwards 2009b). Due to the 
multicollinearity within the dataset with organic growers following distinctly different agronomy compared to conventional growers agronomic factors other than practice were analysed and results presented from the second dataset which included only conventional samples from across both surveys.

\section{Dataset 2 2002-2008 $(n=605)$}

The agronomic factors entered for selection were:

- Year*region

- Intended use

- Previous crop*cultivation

- Variety or Type

- Fungicide applied at flowering (GS59-69)

(* indicates an interaction)

Of the factors tested, intended use and fungicide at flowering were not significant ( $\mathrm{p}=0.56$ and 0.17 , respectively). There were significant interactions between year and region and between previous crop and cultivation. The model accounted for $42 \%$ of the observed variance. The figures below (Fig. 1, 2, 3 and 4) show the back-transformed predicted means for each significant factor and the 95\% confidence limits for the predicted means. For some agronomic factors, there are low numbers of samples, this is usually indicated by large confidence limits (eg samples from N. Ireland).

There was a highly significant $(\mathrm{p}<0.001)$ interaction between year and region with no consistent trend for differences between regions (Fig. 1). Year was the main factor accounting for $21 \%$ of the observed variance. There was a decline in levels from 2006 to 2008.

[Fig 1 here]

Cultivation alone did not have a significant effect on HT2+T2 concentration $(\mathrm{p}=0.059)$. There was, however, a significant interaction between previous crop and cultivation ( $\mathrm{p}=0.027$ ) (Fig. 2). Few samples followed min-till (101 in total, 67 of which were after wheat) and as such there are large confidence limits and no significant differences between HT2+T2 concentration of oats after any previous crop and min-till. For samples after ploughing, there was no significant difference in the HT2+T2 level of oat samples after wheat, barley and oats. The HT2+T2 concentration after cereals was significantly higher than after other crops, which were significantly higher than after grass.

[Fig 2 here] 
Varietal differences were analysed by type (winter or spring) with results showing that winter varieties had a significantly higher mean HT2+T2 concentration compared to spring varieties (Fig. 3). There were 16 winter and 11 spring varieties with 518 and 85 samples respectively. The combination of larger sample size and larger $95 \%$ confidence limits for the winter varieties indicates there was much more variation between HT2+T2 concentrations in the winter compared to the spring varieties. Of the many oat varieties sampled within this dataset, only seven winter and one spring variety were present in sufficient numbers (>10 samples) to allow valid statistical analysis of individual varieties. Of these eight varieties, Gerald was the most common variety, comprising $49 \%$ of total samples, Ayr was the least common of the varieties analysed with only 13 samples. Gerald had significantly higher HT2+T2 than Jalna, SW Dalguise, Grafton and Firth (Fig. 4). As this data is based on observational data, it is important to note that other factors may impact on the predicted means, such as when a variety was grown, for example Ayr was only present in 3 of the 7 years of this dataset when HT2+T2 levels were high (2004-2006).

[Fig 3 and Fig 4 here]

\section{Dataset 3 2006-2008 $(n=279)$}

The agronomic factors entered for selection were:

- Year*region

- Previous cereal*cultivation*debris management

$(*$ indicates an interaction)

Various combinations of inter-related factors were entered into the model after year and region. The interaction of previous crop and other factors could not be analysed due to all the possible combinations with numerous previous crops, which resulted in combinations with no or few samples. For this reason, and based on the results of the second dataset, previous crops were grouped into cereal and non-cereal. Analysis of the interaction of previous crop (cereal or noncereal), debris management (incorporated or baled) and cultivation (ploughed or min-till) identified that debris management and all interactions with debris management were not significant. Previous crop and cultivation and the interaction of the two factors were all significant $(p<0.05)$. To test previous crop history beyond one year, the second, third and fourth year previous crops were included with all interactions. Previous crop from years three and four and all interactions containing these factors were not significant. The interaction of previous crop years one and two and cultivation was significant $(\mathrm{p}=0.005)$ and the final model accounted for $32 \%$ of the observed 
variance. The main significant difference identified was the consistent low levels for samples after ploughing and after two years of non-cereal (Fig. 5). Of these 17 samples, ten were after at least four years under grass. Of more interest is comparison of the means of samples that contained cereal within at least one of the last two years, and were, therefore, within arable rotations prior to oat production. Although not significantly different for these samples, the trends would suggest interactions may exist between cultivation and the last two year's previous crops.

[Fig 5 here]

Dataset 4 2006-2008 (restricted to samples with full cropping history, $n=244$ ))

The agronomic factors entered for selection were:

- Year*region

- Cereal intensity

(* indicates an interaction)

Although previous crops after two years were not significant, the impact of rotations was tested further by including cereal intensity (number of cereal crops in the last four years) within the model. As several samples did not have a full cropping history for all four years, the dataset was filtered of samples lacking this information and re-analysed. Cereal intensity was highly significant $(\mathrm{p}<0.001)$ and accounted for an additional $6.4 \%$ of the observed variance showing a stepwise increase in average HT2+T2 with each additional year of cereal crops within the previous four years (Fig 6). It should be noted that the category of samples with four years of previous cereals would include fields that had more than four years of cereal production and this may explain the greater stepwise increase in HT2+T2 for samples in this category.

[Fig 6 here]

Regression analysis of the annual mean HT2+T2 against monthly weather data identified the best regression was obtained with annual average $\mathrm{HT} 2+\mathrm{T} 2$ concentrations against harvest rainfall (weighted as July $+(\mathrm{July} / 100)^{*}$ August $)$ ). The regression was significant $(\mathrm{p}=0.008)$ and accounted for $74 \%$ of the observed variance (Fig 7). The regression shows a strong negative relationship with higher rainfall resulting in lower HT2+T2 concentrations.

[Fig 7 here] 


\section{Discussion}

Amounts of fusarium mycotoxins, DON and ZON in UK oat samples from 2002-2005 were generally low (Edwards 2009b). This remained the case for 2006-2008 in this study. Legal limits for DON and ZON were only exceeded by a low percentage of samples ( 1 and $6 \%$, respectively) after the delayed wet harvest of 2008. This is in stark contrast to Nordic countries, where DON has become a major problem for oat producers and processors in recent years. For example, from 2004 to 2009 , $20 \%$ of Norwegian oat samples exceeded the EU legal limit for DON in unprocessed oats intended for human consumption (1750 $\left.\mathrm{g} \mathrm{kg}^{-1}\right)$ (Hofgaard, et al. 2016).

There were high incidences and high mean concentrations of fusarium mycotoxins, HT2 and T2 in UK oats identified from harvests 2002-2005 (Edwards 2009b). These high levels continued in the dry summer of 2006. Subsequent years experienced wet summers (2007 and 2008) and a corresponding drop in levels of HT2 and T2. This was confirmed by modelling the mean HT2 and $\mathrm{T} 2$ concentration against harvest rainfall. The negative relationship was significant $(p=0.008)$ and accounted for $74 \%$ of the observed variance. $\mathrm{Xu}$, et al. (2014) conducted window pane analysis on the oat dataset generated in this study (2006-2008) and identified that high HT2+T2 was positively associated with wet weather in early May (pre-flowering) and drier weather from late-May onwards. These results indicate that infection and subsequent HT2 and T2 production is greater when dry weather occurs pre-harvest. This is opposite to what is experienced for DON and ZON in wheat (Cowger et al. 2009, Kharbikar et al. 2015) and opposite to results reported for oats in Norway where high humidity pre-harvest increased the risk of HT2+T2 (Bernhoft, et al. 2012). Differences in results reported in these studies may be due to variation in the time windows analysed. This study used a period of July and August which would cover dough development and ripening in the UK. Bernhoft et al. did not specify the time period but referred to the window as pre-harvest. A recent study by Hjelkrem, et al. (In press) using predicted phenological time windows identified that warm/moderate humid weather during dough development reduced the risk of $\mathrm{HT} 2+\mathrm{T} 2$ accumulation and cool/humid weather during ripening increased the risk of HT2+T2 accumulation in oat grains indicating that there may be a transition in the impact of late summer weather on $\mathrm{HT} 2+\mathrm{T} 2$ risk.

Modelling of HT2+T2 concentration of oat samples against year and region identified a significant interaction for all datasets as reported previously for the 2002-2005 dataset. This is probably due to fluctuation in weather between years and regions. Year accounted for most of the explained variance within the datasets indicating the high seasonality of HT2+T2 contamination in oats. There was no trend from North to South, which would indicate that the temperature range across the UK is not restrictive to HT2 and T2 production on oats. This is different to DON in 
wheat where there was a lower concentration in the North of Britain. Oat samples with more than $1000 \mu \mathrm{g} \mathrm{kg}^{-1} \mathrm{HT} 2+\mathrm{T} 2$ were detected in all regions of the UK.

Agronomic factors were analysed within four datasets based on the availability of data. The previous UK oat mycotoxin study (Edwards 2009b) using the first dataset identified a five-fold lower mean HT2+T2 in organic compared to conventional oats. When analysed in this study there was multicollinearity between the explanatory factors within this dataset as indicated by the impact of moving the position of each explanatory factor within the model. As a result, the models generated from this dataset could identify that practice (organic or conventional), previous crop, cultivation and variety were all significant factors, but it could not determine how important each factor was. Practice was still highly significant when placed at the end of the model which indicated that some other differences in agronomy that occur between the two practices but not included in the model were also important. Analysis of HT2+T2 in harvested oat grains from conventional field experiments previously indicated that inorganic nitrogen fertiliser, plant growth regulator or fungicides were not impacting on the concentration of these toxins (Edwards and Anderson 2011). Bernhoft, et al. (2012) did not find any significant effect of fertiliser, plant growth regulator or pesticides on HT2 in Norwegian oats whilst Pettersson et al. (2008) reported no or small effects of fungicides on HT2+T2 in Sweden. For the combined dataset of 2002-2008 there was no significant effect of fungicides applied at flowering. However, only 54 samples (9\%) received a fungicide during flowering and, therefore, there was limited ability to identify a significant effect.

Previous crop, cultivation and variety were all significant factors using the second dataset (2002-2008 conventional only samples). HT2 and T2 levels were lowest in oats after grass; this is probably because such fields would have been in grass for several years and hence, had a long break from cereals. This result is also seen in the analysis of the third dataset (2006-2008), which was previous cereal over four years in interaction with cultivation and crop management. Two years non-cereal after ploughing was lowest and was largely formed of oat samples after grass. Of more interest, were arable rotations with combinations including cereals. For oats following two years of cereals, the level of HT2+T2 in oats were high, irrespective of the cultivation technique used, whereas, the predicted means for HT2+T2 were higher when one of the last two years crops was a cereal, depending on when the cereal occurred and what cultivation was used. The results appear to indicate (although results were not significantly different) that the inoculum is largely present on cereal crop debris and the risk is increased if either the cereal debris from the last season is not ploughed in or if the cereal debris from two years previous is returned to the surface by ploughing. A previous survey of HT2+T2 in French barley indicated that previous crop was significant, with higher HT2+T2 after a cereal crop, but not cultivation (Orlando, et al. 2009). However, they did not test for an interaction. When this data was re-analysed for an interaction alongside the earlier 
oat dataset (2002-2005) both datasets identified a similar interaction with oats grown after a nonceral and plough had significantly lower HT2+T2 compared to oat crops grown after a cereal and min-till or ploughing (Edwards et al. 2009). Bernhoft, et al. (2012) also identified higher HT2+T2 in Norwegian oats following a cereal. They did not test for an impact of cultivation as the relevant data was only collected in one year and most fields were ploughed (61 of 68 samples). There is very limited data on the impact of rotation on fusarium mycotoxins beyond the previous crop. Schaafsma et al. (2005) found that the crop 2-years-previous had a significant effect on DON in wheat in one out of 4 years studied. Orlando et al. (2009) found that the crop 2-years-previous increased the variance accounted for by a mixed linear model, but was not quite significant for HT2+T2 in French barley. The importance of cereal rotation was further analysed in the fourth dataset (restricted 2006-2008) by cereal intensity (number of last four years in cereal production). This analysis identified a stepwise increase in HT2+T2 concentration with increasing cereal intensity. There was a 10-fold higher level of HT2+T2 in oats following at least four years of previous cereal crops compared to those that were grown after at least four years with no cereal in the rotation. These results show that the intensity of cereal crops within a rotation as well as the most recent previous crop are important in HT2 and T2 risk for oat crops and this factor is probably one of the main contributors to the differences identified between organic and conventional crops observed previous studies (Bernhoft, et al. 2012, Edwards 2009b), as organic growers tend to have long rotations with break crops between cereals.

Analysis of variety by type (winter or spring) identified winter varieties had significantly higher HT2+T2 compared to the spring varieties. This result is the opposite to that reported for French barley where higher HT2+T2 occurred on spring barley (Orlando, et al. 2009) and analysis of sowing date indicated progressively higher HT2+T2 when winter, autumn and spring sown crops were compared. Sowing date rather than the genetics of the varieties grown was confirmed as the risk factor as field experiments with the same varieties of barley sown in the autumn and spring still had higher HT2+T2 in the spring sown plots (Orlando 2009). The ability to compare varieties within surveys of commercial crops is limited as the datasets are highly unbalanced with many varieties poorly represented and the distribution of varieties changes over time as new varieties are marketed. To get a true picture of the differences in HT2+T2 present in varieties studies should be conducted with harvested grains from national variety trials where a large number of varieties can be compared in multiple field experiments under uniform experimental conditions across several years and locations. To identify if differences between winter and spring varieties are due to genetic differences or due to sowing date would require the same varieties to be sown in replicated field experiments at multiple sowing dates as conducted for the French barley varieties (Orlando 2009). 
From 2002-2008 the percentage of oat samples exceeding the EC indicative level for oats intended for human consumption $\left(1000 \mu \mathrm{g} \mathrm{kg}^{-1}\right)$ fluctuated between 1 and 30\%, with an overall average of $16 \%$. This study has identified that there are limited mechanisms by which conventional oat growers can reduce HT2+T2 in oats with intensity of cereals within crop rotations been a major risk factor. The introduction of European legislative maximum limits for HT2 and T2 mycotoxins would have serious implications for UK oat production and oat processing industries based on levels in UK oats determined in this study.

\section{Acknowledgements}

The author gratefully acknowledges the supply of samples and associated agronomic data from crop consultants (AICC members, Agrovista, DARD and Scottish Agronomy) and the funding of this study by AHDB Cereals and Oilseeds (Grant RD-2007-3332). 


\section{References}

Alexander LV, Jones PD. 2000. Updated precipitation series for the U.K. and discussion of recent extremes. Atmospheric Science Letters. 1:142-150.

Anon. 1999. Opinion of the Scientific Committee on Food on Fusarium toxins. Part 1: Deoxynivalenol: European Commission, Brussels (http://ec.europa.eu/food/fs/sc/scf/out44_en.pdf).

Anon. 2004. Opinion of the scientific panel on the contaminants in the food chain on a request from the Commission related to deoxynivalenol (DON) as undesirable substance in animal feed. EFSA Journal. 73:1-41.

Anon. 2013. Commission Recommendation on the presence of T-2 and HT-2 toxin in cereals and cereal products Official Jounal of the European Union. L91:12-15.

Anon. 2006. Commission Regulation (EC) No 1881/2006 setting maximum levels of certain contaminants in foodstuffs. Off J Eur Union. L364:5-24.

Bernhoft A, Clasen PE, Kristoffersen AB, Torp M. 2010. Less Fusarium infestation and mycotoxin contamination in organic than in conventional cereals. Food Addit Contam Part A. 27:842-852.

Bernhoft A, Torp M, Clasen PE, Loes AK, Kristoffersen AB. 2012. Influence of agronomic and climatic factors on Fusarium infestation and mycotoxin contamination of cereals in Norway. Food Addit Contam Part A. 29:1129-1140.

Brodal G, Hofgaard IS, Eriksen GS, Bernhoft A, Sundheim L. 2016. Mycotoxins in organically versus conventionally produced cereal grains and some other crops in temperate regions. World Mycotoxin J. 9:755-770.

Campbell H, Choo TM, Vigier B, Underhill L. 2002. Comparison of mycotoxin profiles among cereal samples from eastern Canada. Canadian Journal of Botany. 80:526-532.

Cowger C, Patton-Ozkurt J, Brown-Guedira G, Perugini L. 2009. Post-Anthesis Moisture Increased Fusarium Head Blight and Deoxynivalenol Levels in North Carolina Winter Wheat. Phytopathology. 99:320-327.

Desjardins AE. 2006. Fusarium Mycotoxins: Chemistry, Genetics and Biology St. Paul, Minnesota: American Phytopathological Society.

Edwards SG. 2004. Influence of agricultural practices on fusarium infection of cereals and subsequent contamination of grain by trichothecene mycotoxins. Toxicol Lett. 153:29-35.

Edwards SG. 2009a. Fusarium mycotoxin content of UK organic and conventional barley. Food Addit Contam Part A. 26:1185-1190.

Edwards SG. 2009b. Fusarium mycotoxin content of UK organic and conventional oats. Food Addit Contam Part A. 26:1063-1069.

Edwards SG. 2009c. Fusarium mycotoxin content of UK organic and conventional wheat. Food Addit Contam Part A. 26:496-506.

Edwards SG, Anderson E. 2011. Impact of agronomy on HT-2 and T-2 toxin content of oats. Plant Breeding and Seed Science. 63:49-57.

Edwards SG, Barrier-Guillot B, Clasen PE, Hietaniemi V, Pettersson H. 2009. Emerging issues of HT-2 and T-2 toxins in European cereal production. World Mycotoxin J. 2:173-179.

Edwards SG, Imathiu SM, Ray RV, Back M, Hare MC. 2012. Molecular studies to identify the Fusarium species responsible for HT-2 and T-2 mycotoxins in UK oats. Int J Food Microbiol. 156:168-175.

EFSA Panel on Contaminants in the Food Chain. 2011. Scientific Opinion on risks for animal and public health related to the presence of T-2 and HT-2 toxin in food and feed. EFSA Journal. 9:2481-2668.

EFSA Panel on Contaminants in the Food Chain. 2017. Scientific opinion on the appropriateness to set a group health based guidance value for T2 and HT2 toxin and its modified forms. EFSA Journal. 15:4655-4707.

Fredlund E, Gidlund A, Sulyok M, Borjesson T, Krska R, Olsen M, Lindblad M. 2013. Deoxynivalenol and other selected Fusarium toxins in Swedish oats - Occurrence and correlation to specific Fusarium species. Int J Food Microbiol. 167:276-283.

Gottschalk C, Barthel J, Engelhardt G, Bauer J, Meyer K. 2007. Occurrence of type A trichothecenes in conventionally and organically produced oats and oat products. Mol Nutr Food Res. 51:1547-1553.

Gourdain E, Piraux F, Barrier-Guillot B. 2011. A model combining agronomic and weather factors to predict occurrence of deoxynivalenol in durum wheat kernels. World Mycotoxin J. 4:129-139. 
Hietaniemi V, Rämö S, Yli-Mattila T, Jestoi M, Peltonen S, Kartio M, Sieviläinen E, Koivisto T, Parikka P. 2016. Updated survey of Fusarium species and toxins in Finnish cereal grains. Food Additives \& Contaminants: Part A. 33:831-848.

Hjelkrem AGR, Aamot HU, Brodal G, Strand EC, Torp T, Edwards SG, Dill-Macky R, Hofgaard IS. In press. HT-2 and T-2 toxins in Norwegian oat grains related to weather conditions at different growth stages. Eur J Plant Pathol.

Hofgaard IS, Aamot HU, Torp T, Jestoi M, Lattanzio VMT, Klemsdal SS, Waalwijk C, Van der Lee T, Brodal G. 2016. Associations between Fusarium species and mycotoxins in oats and spring wheat from farmers' fields in Norway over a six-year period. World Mycotoxin J. 9:365-378.

JECFA. 2011. Evaluation of certain contaminants in food: Seventy-second Report of the Joint FAO/WHO Expert Committee on Food Additives. Geneva: WHO.

Jones RK, Mirocha CJ. 1999. Quality parameters in small grains from Minnesota affected by Fusarium head blight. Plant Dis. 83:506-511.

Kharbikar LL, Dickin ET, Edwards SG. 2015. Impact of post-anthesis rainfall, fungicide and harvesting time on the concentration of deoxynivalenol and zearalenone in wheat. Food Additives \& Contaminants: Part A. 32:2075-2085.

Kuzdralinski A, Solarska E, Mazurkiewicz J. 2013. Mycotoxin content of organic and conventional oats from southeastern Poland. Food Control. 33:68-72.

Langevin F, Eudes F, Comeau A. 2004. Effect of trichothecenes produced by Fusarium graminearum during Fusarium head blight development in six cereal species. Eur J Plant Pathol. 110:735-746.

Langseth W, Elen O. 1996. Differences between barley, oats and wheat in the occurrence of deoxynivalenol and other trichothecenes in Norwegian grain. Journal of Phytopathology-Phytopathologische Zeitschrift. 144:113-118.

Lori GA, Sisterna MN, Sarandon SJ, Rizzo I, Chidichimo H. 2009. Fusarium head blight in wheat: Impact of tillage and other agronomic practices under natural infection. Crop Protect. 28:495-502.

Opoku N, Back M, Edwards SG. 2013. Development of Fusarium langsethiae in commercial cereal production. Eur J Plant Pathol. 136:159-170.

Opoku N, Back M, Edwards SG. In press. Susceptibility of cereal species to Fusarium langsethiae under identical field conditions. Eur J Plant Pathol.

Orlando B. 2009. Qualité sanitaire des orges et des avoines. La recherche progresse sur les toxines T-2 et HT-2. Perspectives Agricoles. 356:6-18.

Orlando B, Barrier-Guillot B, Gourdain E, Maumene C. 2009. Identification of agronomic factors that influence the levels of T-2 and HT-2 toxins in barley grown in France. World Mycotoxin J. 3:169174.

Osborne LE, Stein JM. 2007. Epidemiology of Fusarium head blight on small-grain cereals. Int J Food Microbiol. 119:103-108.

Parry DW, Jenkinson P, McLeod L. 1995. Fusarium Ear Blight (Scab) in Small-Grain Cereals - a Review. Plant Pathol. 44:207-238.

Pettersson H, Borjesson T, Persson L, Lerenius C, Berg G, Gustafsson G. 2008. T-2 and HT-2 toxins in oats grown in Northern Europe. Cereal Research Communications. 36:591-592.

Schaafsma AW, Tamburic-Ilincic L, Hooker DC. 2005. Effect of previous crop, tillage, field size, adjacent crop, and sampling direction on airborne propagules of Gibberella zeae/Fusarium graminearum, fusarium head blight severity, and deoxynivalenol accumulation in winter wheat. Canadian Journal of Plant Pathology. 27:217-224.

Schöneberg T, Martin C, Wettstein FE, Bucheli TD, Mascher F, Bertossa M, Musa T, Keller B, Vogelgsang S. 2016. Fusarium and mycotoxin spectra in Swiss barley are affected by various cropping techniques. Food Additives \& Contaminants Part A, Chemistry, Analysis, Control, Exposure \& Risk Assessment. 33:1608-1619.

Twaruzek M, Blajet-Kosicka A, Wenda-Piesik A, Palubicki J, Grajewski J. 2013. Statistical comparison of Fusarium mycotoxins content in oat grain and related products from two agricultural systems. Food Control. 34:291-295.

Wegulo SN. 2012. Factors influencing deoxynivalenol accumulation in small grain cereals. Toxins. 4:11571180.

Xu X, Madden LV, Edwards SG. 2014. Modeling the effects of environmental conditions on HT2 and T2 toxin accumulation in field oat grains. Phytopathology. 104:57-66. 
Table 1. Concentrations for all mycotoxins detected in UK oats in 2006-2008 (303 samples).

\begin{tabular}{lcccccc}
\hline & & \multicolumn{5}{c}{ Mycotoxin concentration $\left(\mu \mathrm{kg}^{-1}\right)$} \\
\cline { 3 - 7 } & $\%>10 \mu \mathrm{g} \mathrm{kg}^{-1}$ & Mean & Median & $90 \%$ & $95 \%$ & Max \\
\hline NIV & 73 & 57 & 15 & 142 & 224 & 741 \\
FX & 1 & $<10$ & $<10$ & $<10$ & $<10$ & 18 \\
DON & 32 & 28 & $<10$ & 46 & 90 & 1866 \\
NEO & 35 & 13 & $<10$ & 28 & 39 & 225 \\
T2 & 80 & 132 & 45 & 300 & 494 & 2321 \\
HT2 & 85 & 318 & 111 & 711 & 1296 & 6480 \\
HT2+T2 & 87 & 450 & 162 & 979 & 1904 & 8399 \\
ZON & 6 & $<2$ & $<2$ & 3 & 13 & 727 \\
\hline
\end{tabular}

Table 2. Percentage of UK conventional oat samples exceeding legal limits for DON (1750 $\left.\mu \mathrm{g} \mathrm{kg}^{-1}\right)$ and ZON $\left(100 \mu \mathrm{g} \mathrm{kg}^{-1}\right)$ and the combined indicative level for HT2+T2 $\left(1000 \mu \mathrm{g} \mathrm{kg}^{-1}\right)$ for the years 2002-2008 (646 samples).

\begin{tabular}{lccc}
\hline \multirow{2}{*}{ Year } & \multicolumn{3}{c}{ Percentage exceedances } \\
\cline { 2 - 4 } & DON & ZON & HT2+T2 \\
\hline 2002 & 0 & 0 & 10 \\
2003 & 0 & 0 & 29 \\
2004 & 0 & 0 & 15 \\
2005 & 0 & 0 & 30 \\
2006 & 0 & 0 & 21 \\
2007 & 0 & 0 & 8 \\
2008 & 1 & 6 & 1 \\
\hline Overall & 0.14 & 0.86 & 16 \\
\hline
\end{tabular}


Supplementary Table 1. Average percentage recovery and the percentage expanded measurement of uncertainty (\%EMU) for LC/MS/MS quantification of fusarium mycotoxins.

\begin{tabular}{lrr}
\hline Mycotoxin & \% Recovery & \%EMU \\
\hline Nivalenol & 70.2 & 32.4 \\
Deoxynivalenol & 88.2 & 23.0 \\
Fusarenone-X & 101.7 & 32.6 \\
Neosolaniol & 92.8 & 37.2 \\
3-Acetyl-deoxynivalenol & 93.4 & 30.7 \\
15-Acetyl-deoxynivalenol & 88.7 & 37.0 \\
Diacetoxyscirpenol & 90.2 & 28.5 \\
T2 & 89.6 & 34.1 \\
HT2 & 86.3 & 32.4 \\
Zearalenone & 93.1 & 24.0 \\
\hline
\end{tabular}




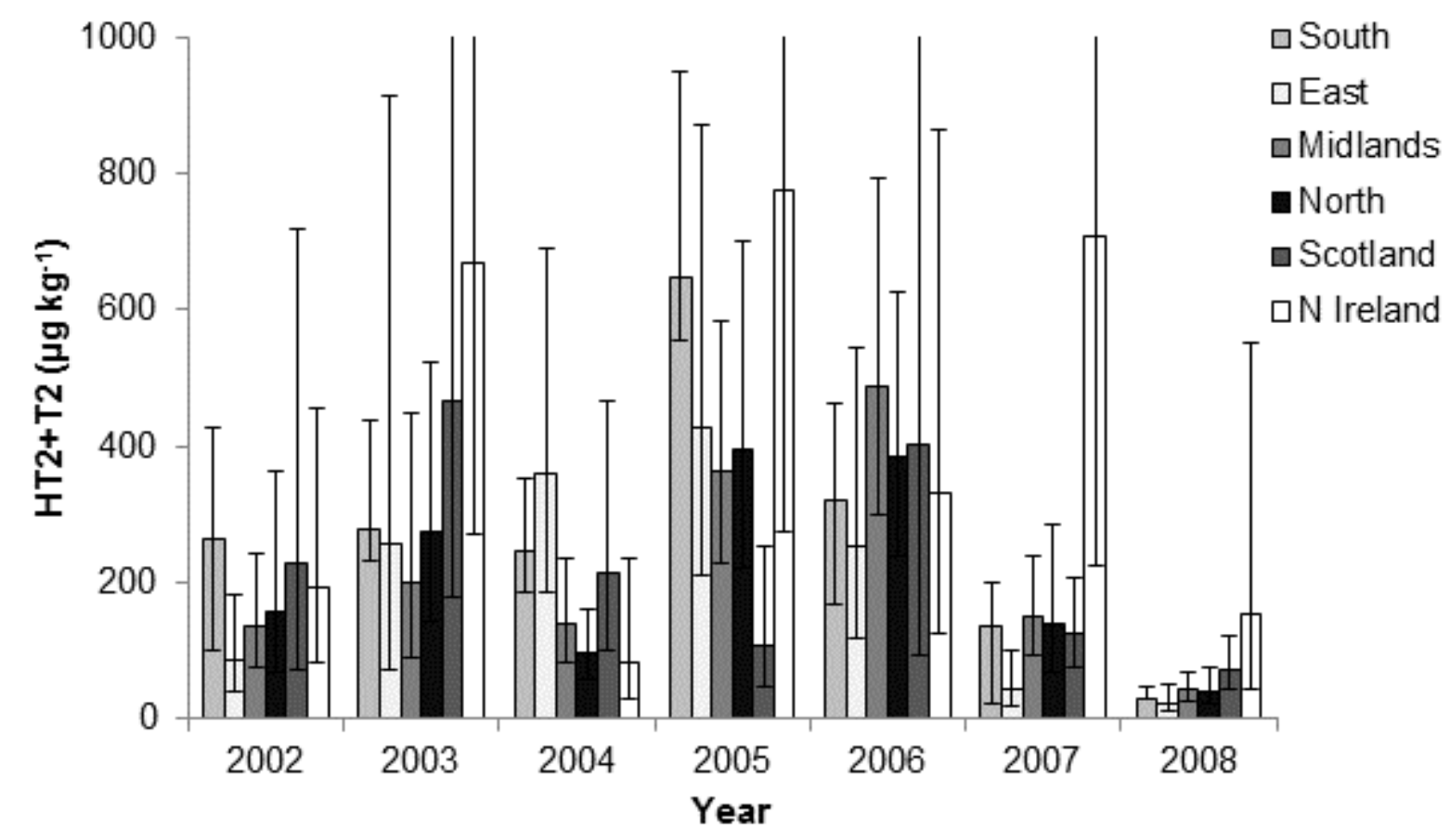

Figure 1. HT2+T2 contamination of oats by region for each year. Error bars represent $95 \%$ confidence limits for predictions.

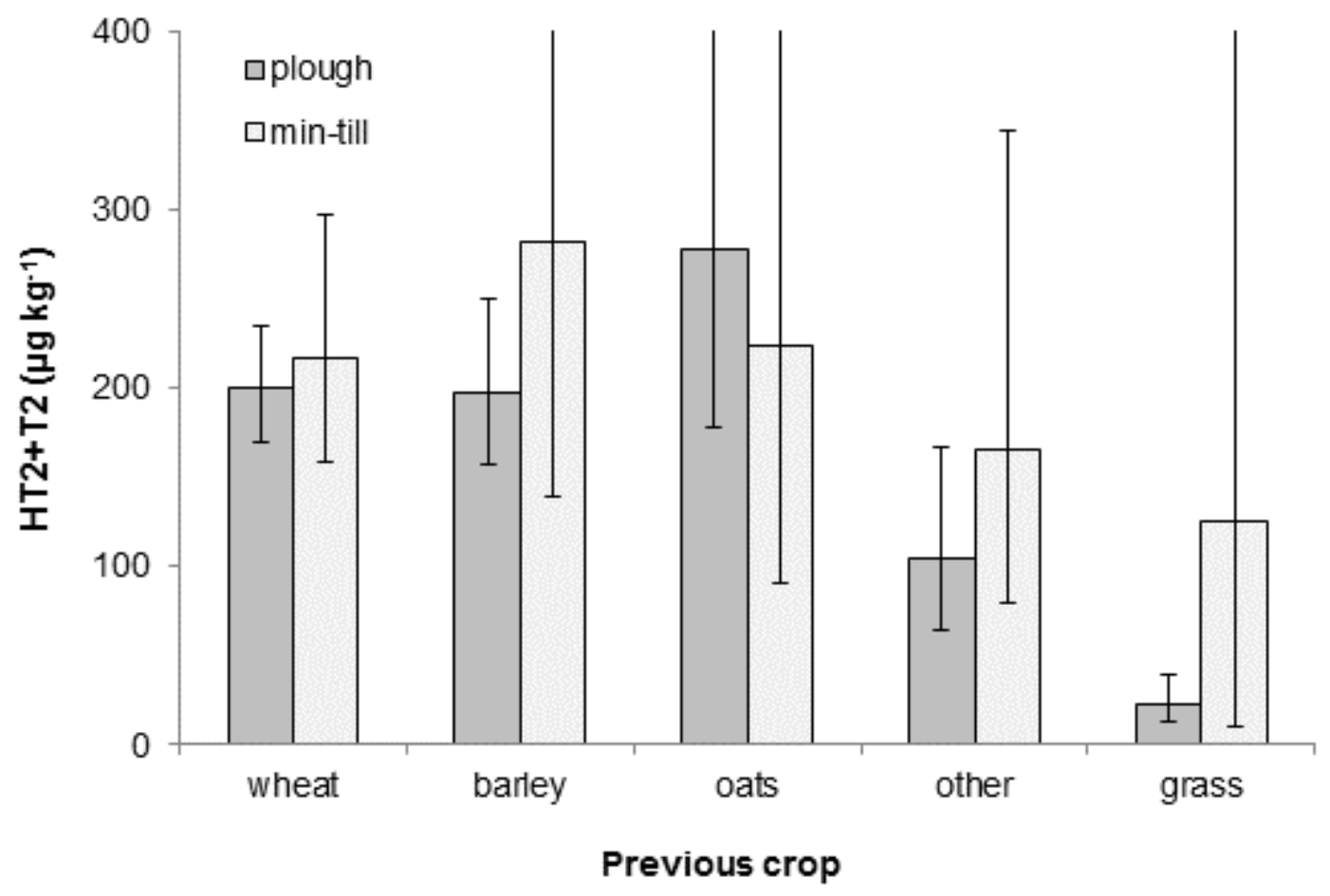

Figure 2. Effect of cultivation and previous crop on HT2+T2 contamination of oats. Error bars represent $95 \%$ confidence limits for predictions. 


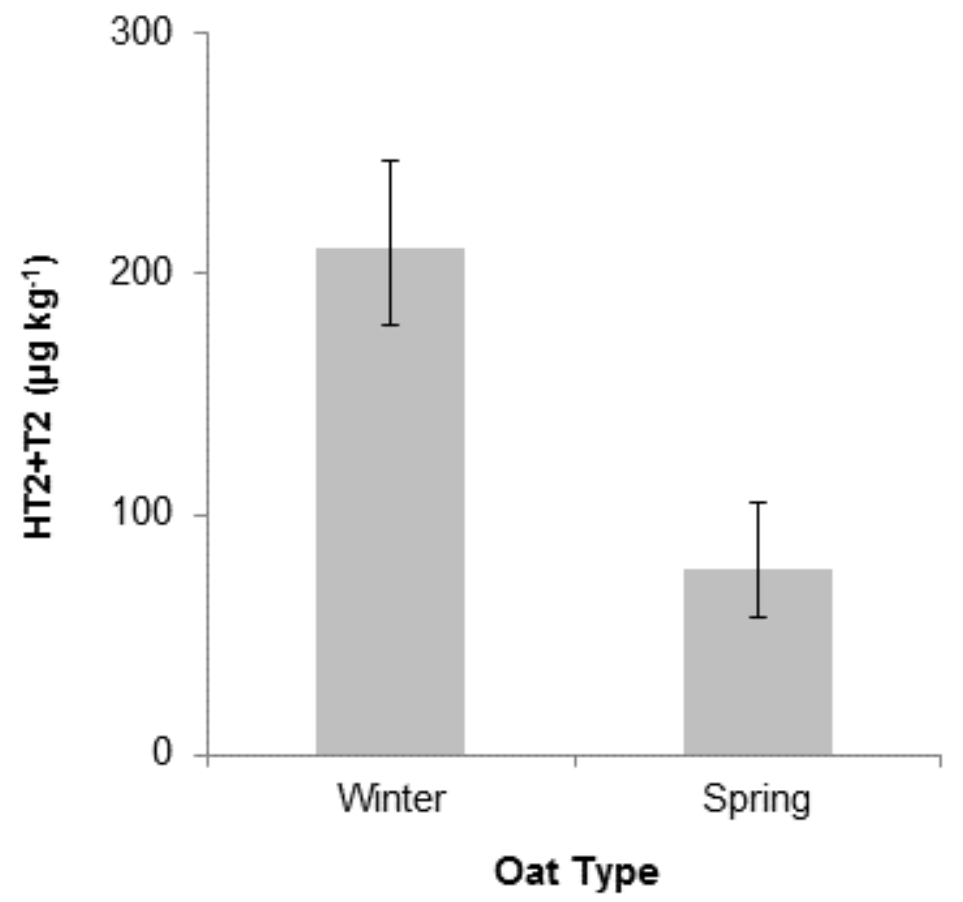

Figure 3. HT2+T2 content of oat type. Error bars represent $95 \%$ confidence limits for predictions.

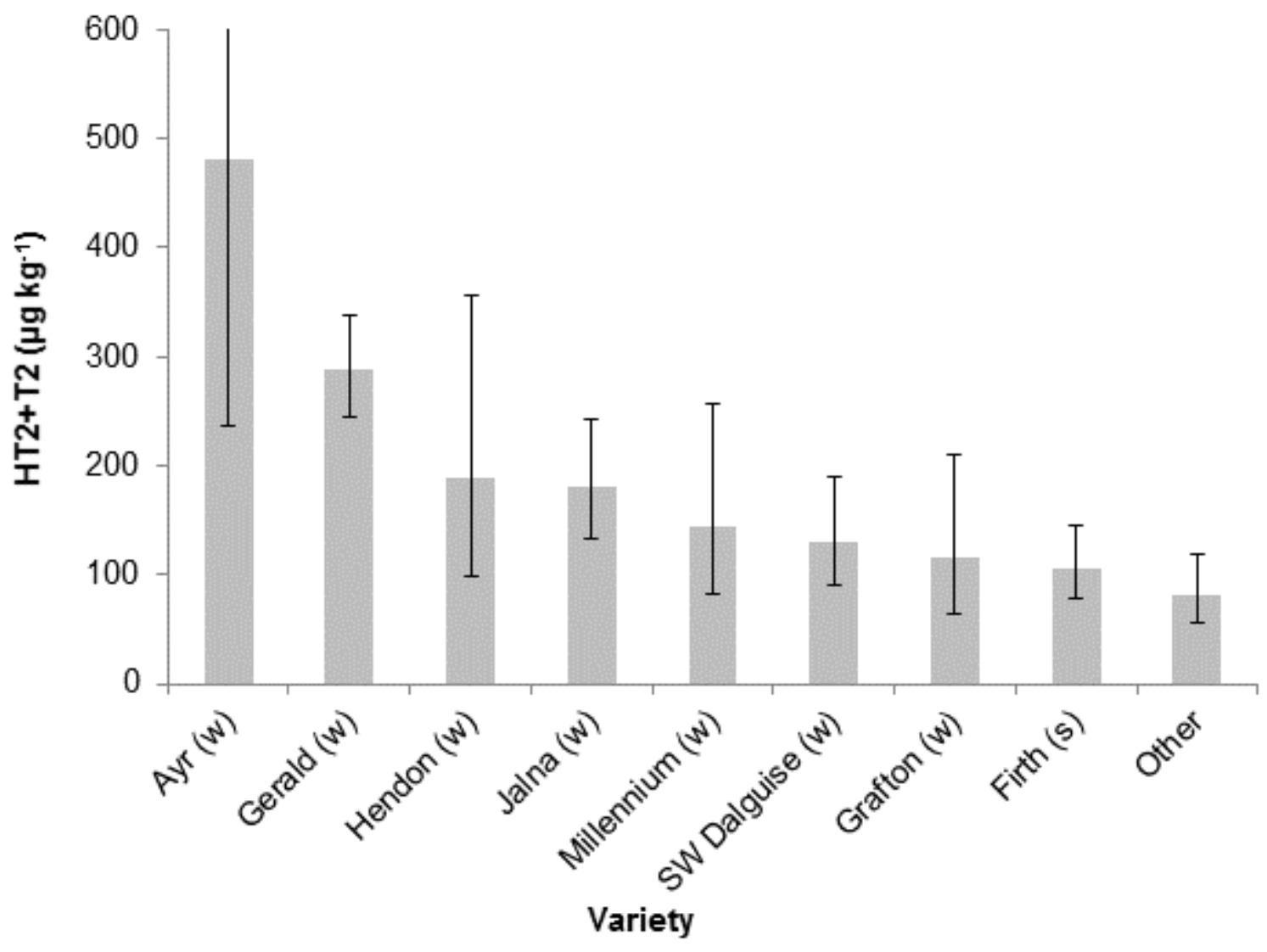

Figure 4. HT2+T2 content of oat varieties. Letters in parenthesis detail the variety type (w, Winter; S, Spring). Error bars represent $95 \%$ confidence limits for predictions. 


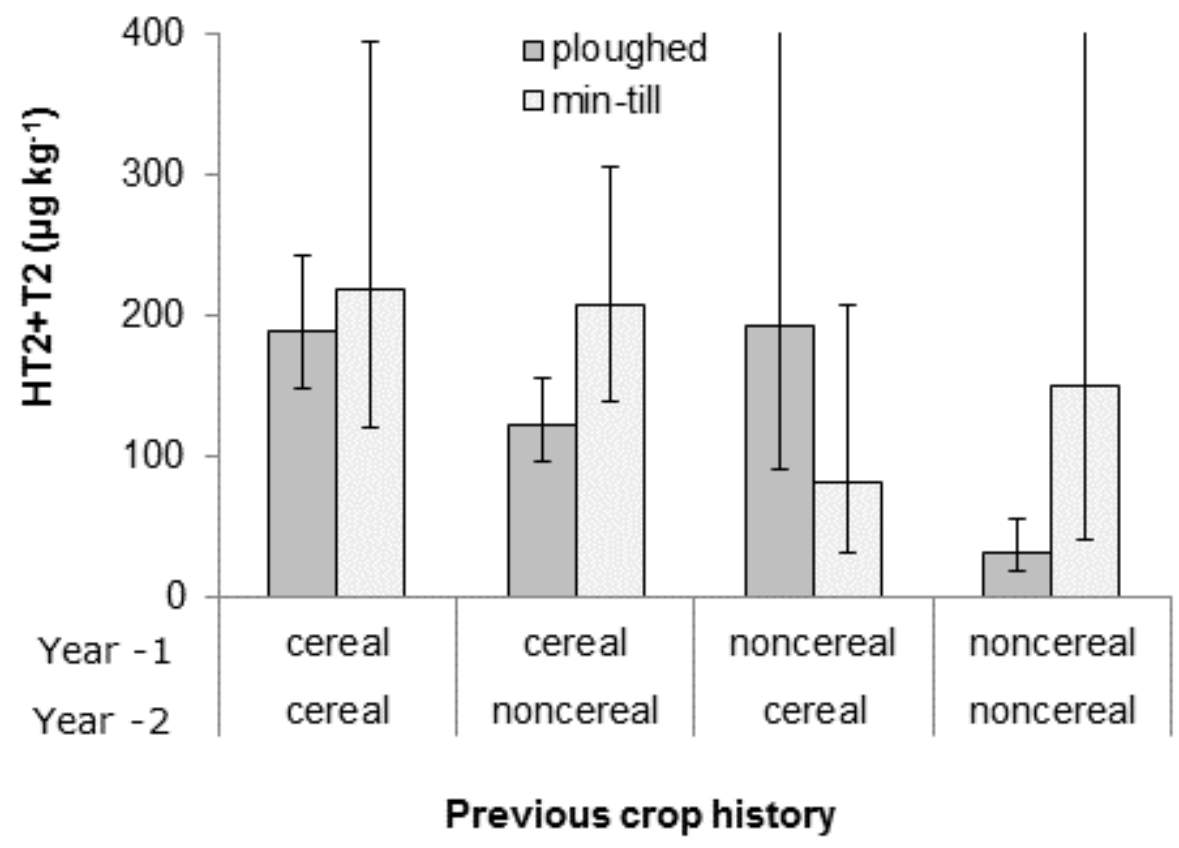

Figure 5. Effect of cultivation and previous crop on HT2+T2 contamination of oats. Error bars represent $95 \%$ confidence limits for predictions.

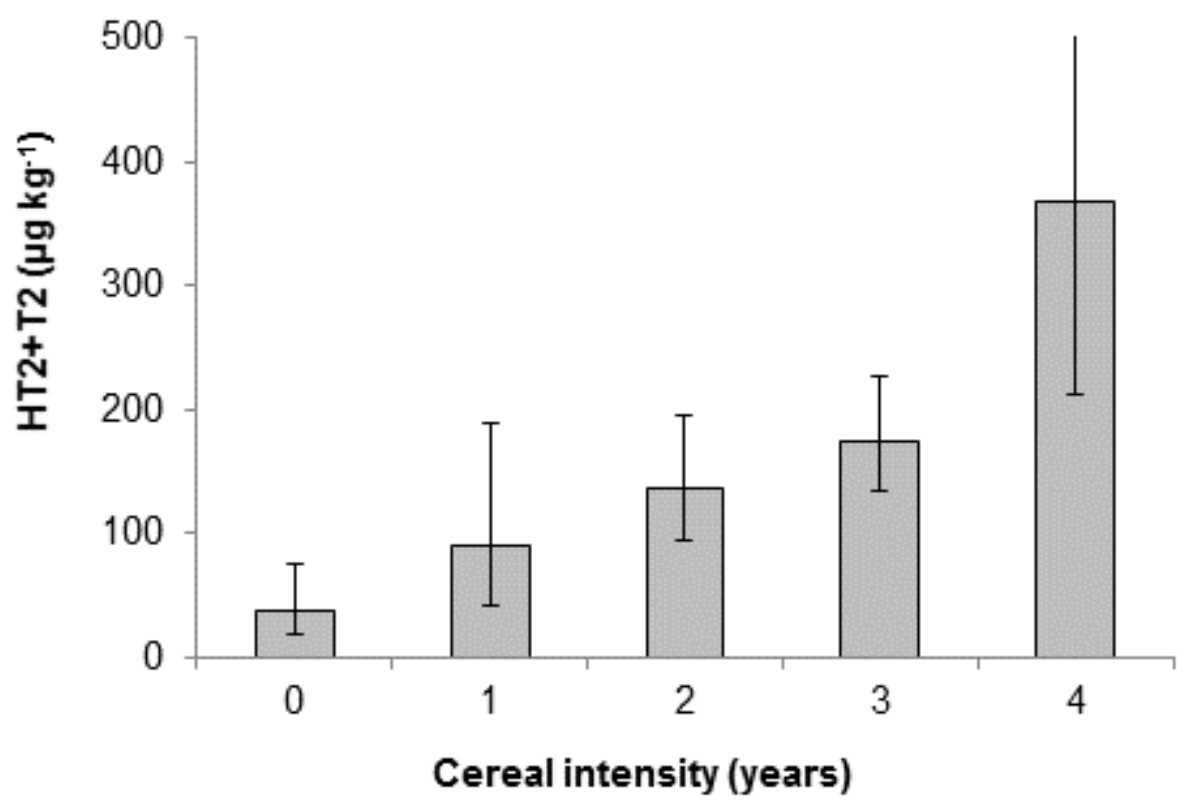

Figure 6. Effect of cereal intensity (number of cereal crops grown in the last four years) on HT2+T2 contamination of oats. Error bars represent 95\% confidence limits for predictions. 


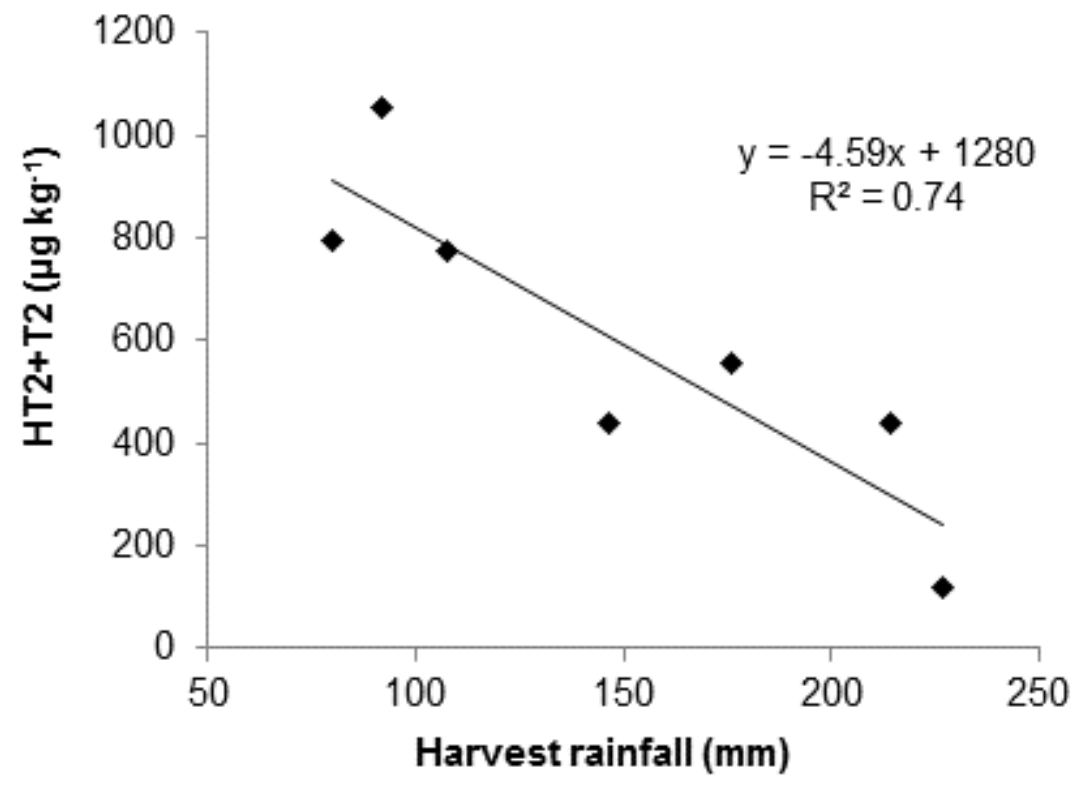

Figure 7. HT2+T2 mean concentration against harvest rainfall for UK oats (2002-2008) 